\title{
5-Fluorouracil combined with apigenin enhances anticancer activity through induction of apoptosis in human breast cancer MDA-MB-453 cells
}

\author{
EUN JEONG CHOI and GUN-HEE KIM \\ Plant Resources Research Institute, Duksung Women's University, \\ 419 Ssangmun-dong, Tobong-ku, Seoul 132-714, Korea
}

Received July 14, 2009; Accepted September 3, 2009

DOI: 10.3892/or_00000598

\begin{abstract}
We investigated the effects of combined treatment with 5-fluorouracil and apigenin on proliferation and apoptosis, as well as the underlying mechanism, in human breast cancer MDA-MB-453 cells. The MDA-MB-453 cells, which have been shown to overexpress ErbB2, were resistant to 5-fluorouracil; 5-fluorouracil exhibited a small dose-dependent anti-proliferative effect, with an $\mathrm{IC}_{50}$ of $90 \mu \mathrm{M}$. Interestingly, combined treatment with apigenin significantly decreased the resistance. Cellular proliferation was significantly inhibited in cells exposed to 5-fluorouracil at its $\mathrm{IC}_{50}$ and apigenin $(5,10,50$ and $100 \mu \mathrm{M})$, compared with proliferation in cells exposed to 5-fluorouracil alone. This inhibition in turn led to apoptosis, as evidenced by an increased number of apoptotic cells and the activation of caspase- 3 . To investigate the mechanism by which the combination of 5-fluorouracil and apigenin induces apoptosis, ErbB2 expression was analyzed. The level of ErbB2 was unchanged by 5-fluorouracil alone but was drastically reduced in cells treated with 5-fluorouracil plus apigenin. Moreover, compared with 5-fluorouracil alone, 5-fluorouracil in combination with apigenin at concentrations $>10 \mu \mathrm{M}$ exerted a pro-apoptotic effect via the inhibition of Akt expression. Taken together, our results suggest that 5fluorouracil acts synergistically with apigenin inhibiting cell growth and inducing apoptosis via the down-regulation of ErbB2 expression and Akt signaling.
\end{abstract}

\section{Introduction}

Breast cancer is one of the most frequently diagnosed cancers in women, and its occurrence has been increasing in recent years. It is now the major cause of mortality and morbidity in

Correspondence to: Dr Eun Jeong Choi, Plant Resources Research Institute, Duksung Women's University, 419 Ssangmun-dong, Tobong-ku, Seoul 132-714, Korea

E-mail: ejchoi@duksung.ac.kr

Key words: apoptosis, Akt pathway, apigenin, ErbB2, MDA-MB453 cells
Korean women, which may be attributable to changes from traditional to westernized lifestyles.

As a chemotherapy agent, 5-fluorouracil, an active metabolite of capecitabine, is widely used for the treatment of solid tumors such as breast cancers $(1,2)$. However, the development of resistance is a major problem in the use of drugs such as 5-fluorouracil and limits the clinical utility of the drug. Attempts to solve this problem have taken various approaches, including the combined use of cancer drugs. In addition, it was recently shown that combined treatment with natural phytochemicals increased the efficiency and reduced the cytotoxicity of some cancer drugs.

Apigenin (4',5,7-trihydroxyflavone) is a member of the flavone subclass of flavonoids present in fruits and vegetables (3) and is considered to have various biological activities such as anti-inflammatory, anticancer and free-radical scavenging properties (4-7). Studies of human malignant cancer cell lines have shown that apigenin inhibits cancer cell growth via the promotion of cell cycle arrest and apoptosis $(8,9)$. As a candidate anticancer agent, apigenin is of particular interest because it exhibits selective induction of cell cycle arrest and apoptosis in human prostate carcinoma cells without affecting normal cells $(10,11)$. Moreover, apigenin is non-mutagenic and less cytotoxic than other flavonoids (12).

Therefore, in this study, we investigated the effects of 5-fluorouracil combined with apigenin on cellular proliferation and apoptosis using human breast cancer MDA-MB-453 cells, and we explored the underlying mechanism.

\section{Materials and methods}

Cell culture and apigenin treatment. Human breast cancer MDA-MB-453 cells were purchased from the KCLB (Korean Cell Line Bank, Korea). Cells was routinely maintained in RPMI-1640 (Gibco), supplemented with 10\% FBS and antibiotics $(50 \mathrm{U} / \mathrm{ml}$ of penicillin and $50 \mu \mathrm{g} / \mathrm{ml}$ streptomycin, Gibco) at $37^{\circ} \mathrm{C}$ in a humidified atmosphere containing $5 \% \mathrm{CO}_{2}$. In cell proliferation analysis experiments, cells were treated with either 5-fluorouracil or apigenin alone, or vehicle alone for 24, 48 and $72 \mathrm{~h}$. For apoptosis assay, cells were treated with 5-fluorouracil or apigenin either alone or combined, or vehicle alone for $72 \mathrm{~h}$. Apigenin and 5-fluorouracil was purchased from Sigma and dissolved in DMSO (final concentration $0.1 \%$ in medium). 


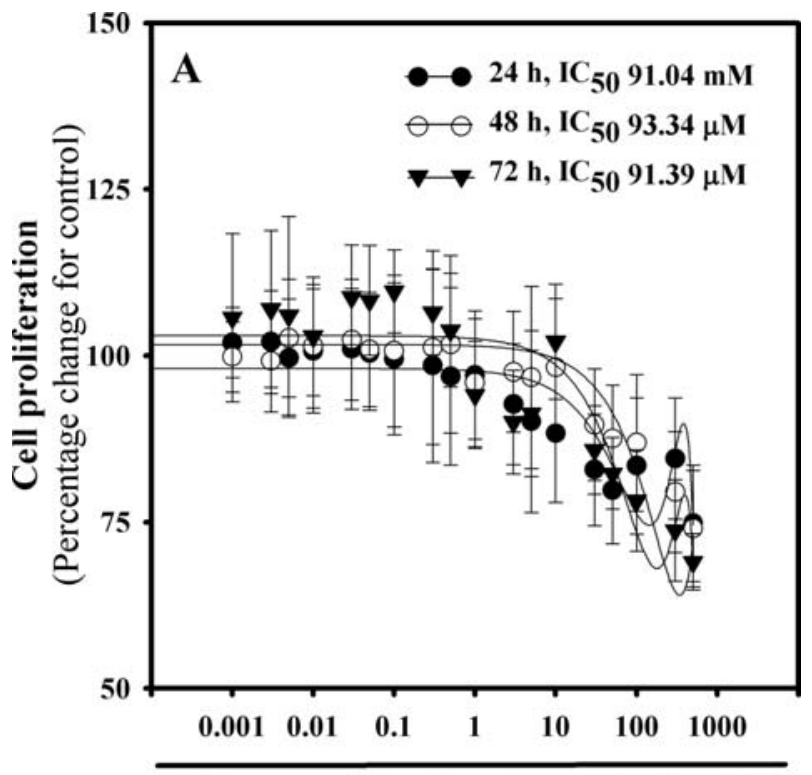

5-Fluorouracil treatment concentration $(\mu \mathrm{M})$

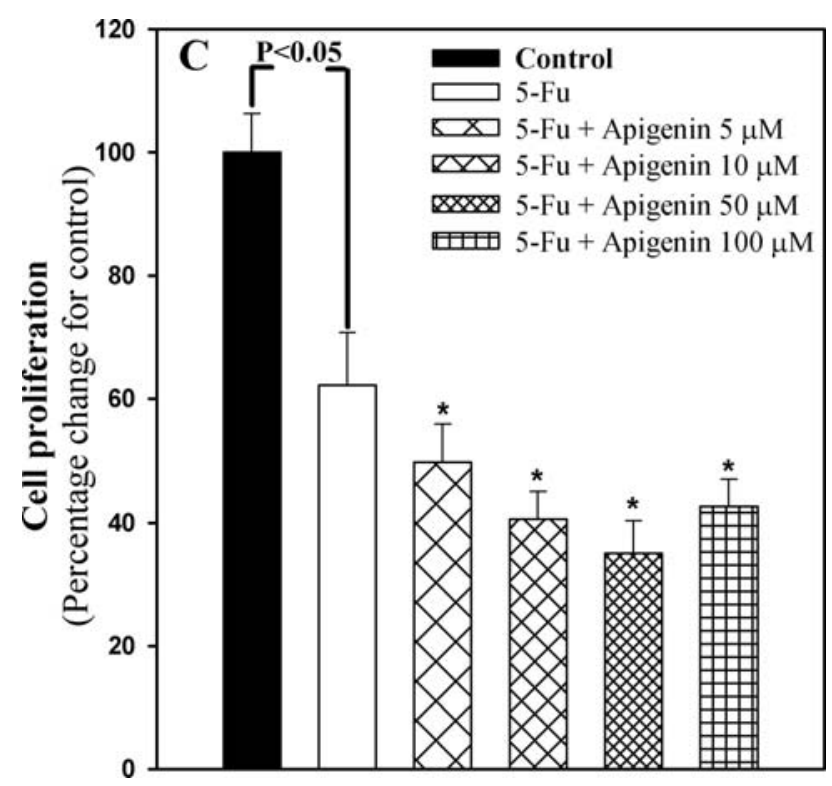

Figure 1. Effect of apigenin or 5-fluorouracil on cell proliferation of human breast cancer MDA-MB-453 cells. (A and B) Cells were exposed to either 5-fluorouracil (0.001-500 $\mu \mathrm{M})$ or apigenin (1-100 $\mu \mathrm{M})$ and incubated for 24, 48 and $72 \mathrm{~h}$. (C) Cells were exposed to 5 -fluorouracil at its $\mathrm{IC}_{50}$ concentration with apigenin $(5,10,50$ and $100 \mu \mathrm{M})$ for $72 \mathrm{~h}$. All data are reported as the percentage change in comparison with the vehicle-only group, which were arbitrarily assigned $100 \%$ viability. ${ }^{*} \mathrm{P}<0.05$, significantly different from the vehicle-only group $(0.1 \%$ DMSO in medium, that is, apigenin concentration $=0$ ).

Cell proliferation and cell death assay. Cell proliferation was determined using the MTT assay. Methyl thiazolyl tetrazolium (MTT) was added in cells exposed to either 5-fluorouracil or apigenin. Four hours later, DMSO was added to each well to dissolve the resulting formazan crystals and then absorbance was recorded at $490 \mathrm{~nm}$ in a microplate reader (SpectraMax Plus; Molecular Devices). The value of $\mathrm{IC}_{50}$ (i.e., the concentration of the extract required to inhibit cancer cell proliferation by $50 \%$ of the control level, which is each cells treated with only compound solvent) was estimated from the plot.

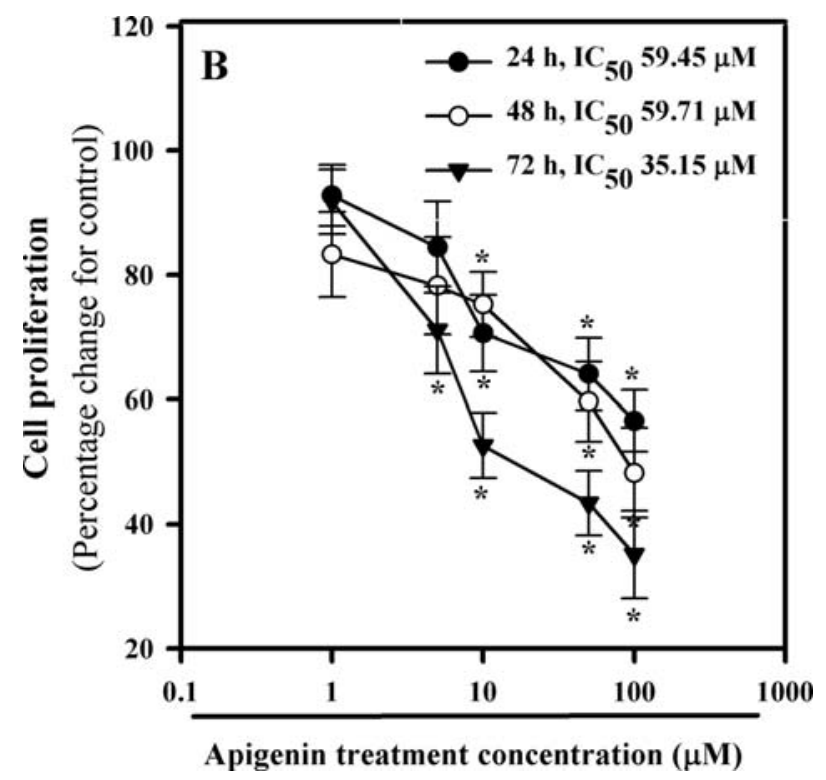

Cell apoptosis assay. Annexin V-FITC apoptosis kit (BD ApoAlert ${ }^{\mathrm{TM}}$, BD Biosciences Clontech, CA, USA) was used for apoptosis detection. Cells were trypsinized, washed twice in ice-cold PBS, and resuspended in $500 \mu 1$ binding buffer (Sigma). Annexin V and propidium iodide solution were added to the cell preparations and incubated for $25 \mathrm{~min}$ in the dark. Binding buffer (400 $\mu 1)$ was then added to each tube and the samples were analyzed by a FACS Calibur instrument (BD Biosciences) equipped with CellQuest 3.3 software.

Immunoblotting assay. Cells were lysed in RIPA buffer (1\% NP-40, $150 \mathrm{mM} \mathrm{NaCl}, 0.05 \%$ DOC, 1\% SDS, $50 \mathrm{mM}$ Tris, $\mathrm{pH}$ 7.5) containing protease inhibitor for $1 \mathrm{~h}$ at $4^{\circ} \mathrm{C}$. The supernatant was separated by centrifugation, and protein concentration was determined by Bradford protein assay kit II (Bio-Rad Laboratories, CA, USA). Proteins (25 $\mu \mathrm{g} / \mathrm{well})$ denatured with sample buffer were separated by $10 \%$ SDSpolyacrylamide gel. Proteins were transferred onto nitrocellulose membranes $(0.45 \mu \mathrm{m})$. The membranes were blocked with a $1 \%$ BSA solution for $3 \mathrm{~h}$ and washed twice with PBS containing $0.2 \%$ Tween-20, and incubated with the primary antibody overnight at $4{ }^{\circ} \mathrm{C}$. Antibodies against cleaved caspase- 3 and $B$-actin were purchased from Santa Cruz (Santa Cruz Biotechnology, Inc., CA, USA) and used to probe the separate membranes. ErbB2, Akt, and phosphorAkt were purchased from the Cell Signalling (Cell Signaling Technology, Inc., CA, USA), and caspase- 3 and $\beta$-actin were purchased from Santa Cruz (Santa Cruz Biotechnology, Inc.). The next day, the immunoreaction was continued with the secondary goat anti-rabbit horseradish-peroxidaseconjugated antibody after washing for $2 \mathrm{~h}$ at room temperature. The specific protein bands were detected by Opti-4CN Substrate kit (Bio-Rad).

Apoptosis detection. For annexin-based FACS analysis, cells were trypsinized, washed twice in ice-cold PBS, and resuspended in $500 \mu \mathrm{l}$ binding buffer (Sigma). Annexin V and propidium iodide solution were added to the cell preparations 
and incubated for $25 \mathrm{~min}$ in the dark. Binding buffer (400 $\mu \mathrm{l})$ was then added to each tube and the samples were analyzed by a FACS Calibur instrument equipped with CellQuest 3.3 software.

For caspase- 3 activity analysis, cells were collected by trypsinization and lysed with lysis buffer (1\% Triton X-100, $0.32 \mathrm{M}$ sucrose, $5 \mathrm{mM}$ EDTA, $10 \mathrm{mM}$ Tris- $\mathrm{HCl}, \mathrm{pH}$ 8.0, $2 \mathrm{mM}$ DTT, $1 \mathrm{mM}$ PMSF, $1 \mu \mathrm{g} / \mathrm{ml}$ aprotinin, $1 \mathrm{mg} / \mathrm{ml}$ leupeptin). Thereafter, the lysates were transferred to wells in a 96-well flat-bottom plate. A peptide with the caspase-3 target motif DEVD bound to the chromophore $p$-nitroanilide was added and incubated at $37^{\circ} \mathrm{C}$ for $1 \mathrm{~h}$. The intensity of the developed color was read at $405 \mathrm{~nm}$ in a microplate reader. In addition, cleaved caspase- 3 expression was determined using immunoblotting assay as described above.

Statistical analyses. All data were expressed as percent compared with vehicle-treated control cells, which were arbitrarily assigned $100 \%$. Data were analyzed by one-way analysis of variance followed by Dunnett's multiple comparison test (Sigma Stat, Jandel, San Rafael, CA, USA). For all comparisons, differences were considered statistically significant at $\mathrm{P}<0.05$.

\section{Results}

Effect of 5-fluorouracil or apigenin on the cell proliferation of human breast cancer MDA-MB-453 cells. As presented in Fig. 1, the effects of 5-fluorouracil or apigenin on the cell proliferation of human breast cancer MDA-MB-453 cells were measured with the MTT assay. 5-Fluorouracil exhibited a small dose-dependent anti-proliferative effect, with an $\mathrm{IC}_{50}$ of $90 \mu \mathrm{M}$ regardless of treatment time (Fig. 1A). In contrast, apigenin significantly inhibited cellular proliferation in a dose- and time-dependent manner $(\mathrm{P}<0.05$, Fig. 1B); a significant anti-proliferative effect was observed in cells exposed to $5 \mu \mathrm{M}$ apigenin for $72 \mathrm{~h}$.

To determine the conditions necessary to produce a synergistic effect between the two compounds, cellular proliferation was investigated in cells exposed to 5-fluorouracil at its $\mathrm{IC}_{50}$ and apigenin at concentrations exceeding $5 \mu \mathrm{M}$ (Fig. 1C). Combined treatment with 5-fluorouracil and $10 \mu \mathrm{M}$ apigenin produced a first significant anti-proliferative effect. There was no significant difference in the anti-proliferative effect among the combined treatments with different concentrations of apigenin; all of the combined treatments produced a 56$68 \%$ reduction in proliferation, compared with that produced by 5 -fluorouracil alone.

Effect of 5-fluorouracil or apigenin on ErbB2 and Akt expression of human breast cancer MDA-MB-453 cells. Compared with MCF-7 cells, MDA-MB-453 cells were shown to overexpress ErbB2 (Fig. 2A). Although the treatment of MDA-MB-453 cells with 5-fluorouracil alone slightly lowered ErbB2 expression compared with the expression in control cells, a significantly greater reduction was observed following combined treatment with 5-fluorouracil and 50 or $100 \mu \mathrm{M}$ apigenin.

Under the conditions described above (i.e., MDA-MB-453 cells exposed to 5 -fluorouracil at its $\mathrm{IC}_{50}$ combined with

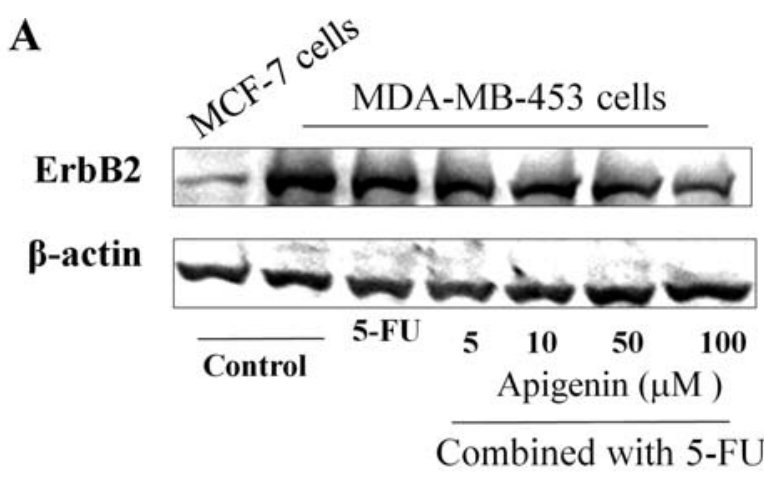

B

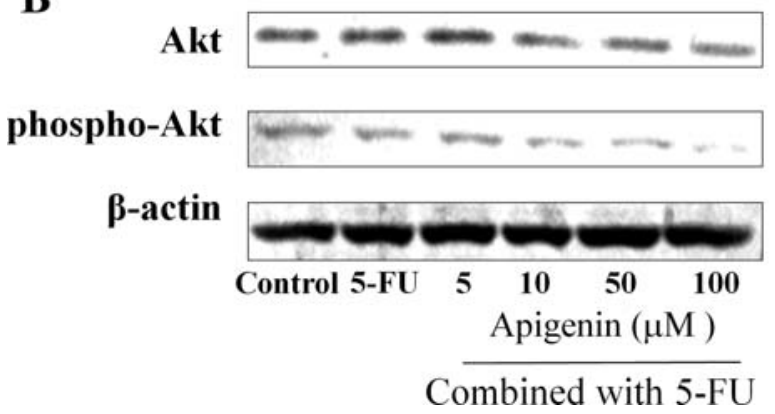

Figure 2. Effect of 5-fluorouracil combined with apigenin on ErbB2 (A) and Akt (B) expresssions of human breast cancer MDA-MB-453 cells. MDAMB-453 cells were exposed to 5-fluorouracil at its $\mathrm{IC}_{50}$ concentration combined with apigenin $(5,10,50$ and $100 \mu \mathrm{M})$ for $72 \mathrm{~h}$.

apigenin at 5, 10, 50 or $100 \mu \mathrm{M}$ for $72 \mathrm{~h}$ ), Akt expression and Akt phosphorylation were significantly decreased (Fig. 2B).

Effect of 5-fluorouracil combined with apigenin on the apoptosis induction of human breast cancer MDA-MB-453 cells. Treatment with 5-fluorouracil alone significantly increased the number of apoptotic cells, by $31.49 \%$ compared with control cells (Fig. 3A). In comparison, combined treatment with 5-fluorouracil and apigenin at concentrations $>10 \mu \mathrm{M}$ significantly increased the number of apoptotic cells by $\sim 50 \%$ compared with the increase in apoptosis with 5fluorouracil alone $(\mathrm{P}<0.05)$.

As shown in Fig. 3B, cleaved caspase-3 expression was clearly increased by treatment with 5-fluorouracil and apigenin. Consistent with this result, a significant increase in caspase-3 activity was observed in cells exposed to 5-fluorouracil and apigenin at concentrations exceeding $10 \mu \mathrm{M}$. Combined treatment with apigenin at 50 or $100 \mu \mathrm{M}$ increased caspase-3 activity by 1.6- and 1.7-fold, respectively, compared with the activity in cells treated with 5-fluorouracil alone.

\section{Discussion}

Apigenin has been shown to efficiently inhibit proliferation in various breast cancer cell lines $(13,14)$, which is in agreement with our results showing the dose- and timedependent inhibition of human breast cancer MDA-MB-453 cell proliferation by apigenin. In contrast, the anti-proliferative effects of 5-fluorouracil were observed only at concen- 

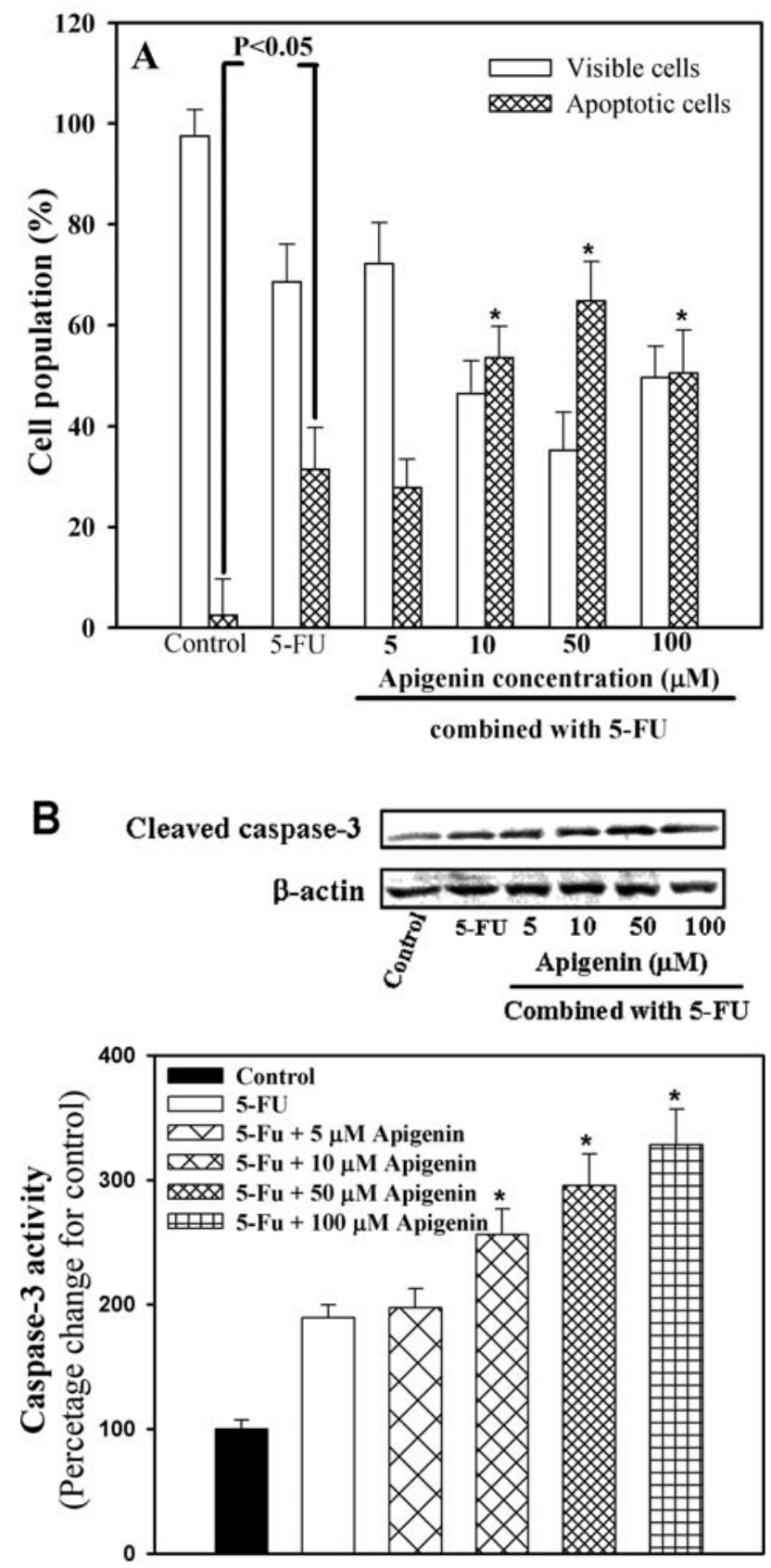

Figure 3. Effect of 5-fluorouracil combined with apigenin on apoptosis induction of human breast cancer MDA-MB-453 cells. Cells were exposed to 5-fluorouracil at its $\mathrm{IC}_{50}$ concentration combined with apigenin $(5,10,50$ and $100 \mu \mathrm{M}$ ) for $72 \mathrm{~h}$. Apoptosis was determined using Annexin V-FITC apoptosis kit (A), caspase-3 expression and its activity (B). "P<0 05 , significantly different from the vehicle-only group $(0.1 \%$ DMSO in medium, that is, 5 -fluorouracil or apigenin concentration $=0$ ).

trations higher than those of apigenin $\left(\mathrm{IC}_{50}=35.15 \mu \mathrm{M}\right)$. Previous studies have reported an $\mathrm{IC}_{50}$ of greater than $170 \mu \mathrm{M}$ 5-fluorouracil in MDA-MB-453 cells (15). In the present study, treatment with 5-fluorouracil combined with apigenin at concentrations greater than $10 \mu \mathrm{M}$ produced a significant anti-proliferative effect compared with that produced by treatment with 5-fluorouracil alone.

The reason for the poor response to 5-fluorouracil alone may be that the overexpression of ErbB2 renders human breast cancer cells more resistant to certain chemotherapeutic agents $(15,16)$. It has been reported that $E r b B 2$ is distinct from other tumor-promoting genes in that it enhances the intrinsic metastatic potential of MDA-MB-435 cells without increasing their capacity for transformation (16). ErbB2 (HER-2/neu) encodes a 185-kDa transmembrane glycoprotein (ErbB2) that belongs to the epidermal growth factor receptor family of type I receptor tyrosine kinases (ErbB family). ErbB2 overexpression has been reported in approximately $25-30 \%$ of human breast cancers $(17,18)$.

Several mechanisms have been proposed to explain the inhibition of cancer cell growth by apigenin; these include the arrest of the cell cycle, the induction of apoptosis, and the modulation of signal transduction $(19,20)$. It has been suggested that apigenin-induced apoptosis results from the depletion of ErbB2 following the dissociation of a complex containing ErbB2 and GRP94 $(8,21)$. Aberrant ErbB2 receptor tyrosine kinase expression in breast tumor or cancer cell lines affects a range of signal transduction pathways that regulate basic cellular processes such as proliferation and survival $(15,16,22)$.

In the present study, ErbB2 expression was higher in MDA-MB-453 cells than in MCF-7 cells. Exposure to 5fluorouracil alone did not affect the expression of ErbB2 in MDA-MB-453 cells; however, combined treatment with 5fluorouracil and apigenin at 50 or $100 \mu \mathrm{M}$ strongly decreased ErbB2 expression. Structure-activity analyses (21) indicate that flavonoid induced down-regulation of ErbB2 in dependent with the presence of a B ring, a 3',4'-hydroxyl group, and a 2-phenyl group on the flavonoids structure. Notably, apigenin has these features and, in combination with 5fluorouracil, appears to efficiently down-regulate ErbB2 expression.

The serine/threonine kinase protein kinase B or Akt (PKB/ Akt), is a downstream target of phosphoinositide 3-kinase (PI3K), which is activated as a result of the ligand-dependent activation of receptor tyrosine kinases such as those of the ErbB receptor family. Akt plays critical regulatory roles in mammalian cell signaling, affecting such divergent cellular processes as apoptosis, cellular proliferation, differentiation, and metabolism $(23,24)$. Akt is also activated in various cancer cells, and thus Akt signaling has become a target for cancer chemotherapy.

Flavonoids such as genistein and quercetin have been shown to play a role in Akt signaling $(25,26)$, and the inhibition of Akt activity may facilitate the inhibition of proliferation and the induction of apoptosis in cancer cells. Several reports have suggested that apigenin exerts its anticancer effects by blocking the Akt pathway $(25,27,28)$. In the present study, 5-fluorouracil combined with apigenin decreased both the expression and phosphorylation of Akt in an apigenin dosedependent manner. Thus, the inhibition of the Akt pathway may be an important mechanism underlying the effects of 5-fluorouracil combined with apigenin in human breast cancer MDA-MB-453 cells.

To further scrutinize these results, we used fluorescenceactivated cell sorting FACS to analyze apoptosis in MDAMB-453 cells treated with 5-fluorouracil and apigenin, using the experimental conditions described above. Similar to the results of our cell proliferation experiments, combined treatment with 5-fluorouracil and apigenin increased the frequency 
of apoptosis, particularly at higher concentrations of apigenin (over $50 \mu \mathrm{M}$ ), compared with treatment with 5-fluorouracil alone.

Another biomarker of apoptosis, caspase-3 expression and activity, was also considered. Caspase- 3 is a major death protease that catalyzes the cleavage of many key cellular proteins. In the present study, the activity of caspase- 3 was significantly increased in cells exposed to 5-fluorouracil and apigenin at 50 or $100 \mu \mathrm{M}$. Thus, 5-fluorouracil and apigenin appear to have synergistic effects on the induction of apoptosis, at high concentrations of apigenin.

Based on the obtained results, 5-fluorouracil combined with apigenin exhibits anticancer activity via the inhibition of cellular proliferation and the induction of apoptosis. The present study is the first to show that treatment with 5-fluorouracil combined with apigenin stimulates the response of human breast cancer MDA-MB-453 cells to 5-fluorouracil. The significant effect of apigenin on the response to 5fluorouracil appears to be mediated via the down-regulation of ErbB2 and Akt signaling. The present study suggests that these findings are encouraging for the clinical use of 5-fluorouracil in human breast cancers.

\section{Acknowledgements}

This study was supported by National Research Foundation of Korea Grant funded by the Korean Government (KRF2008-005-J00601).

\section{References}

1. Bunnell CA and Winer EP: Oral 5-FU analogues in the treatment of breast cancer. Oncology 12: 39-43, 1998.

2. Cameron DA, Gabra $\mathrm{H}$ and Leonard RC: Continuous 5 fluorouracil in the treatment of breast cancer. Br J Cancer 70 . 120-124, 1994

3. Miean KH and Mohamed S: Flavonoid (myricetin, quercetin, kaempferol, luteolin and apigenin) content of edible tropica plants. J Agric Food Chem 49: 3106-3112, 2001

4. Soares R and Azevedo I: Apigenin: is it a pro- or anti-inflammatory agent? Am J Pathol 168: 1762-1763, 2006.

5. Fuchs J and Milbradt R: Skin anti-inflammatory activity of apigenin-7-glucoside in rats. Arzneimittelforschung 43: 370-372, 1993.

6. Singh JP, Selvendiran K, Banu SM, Padmavathi R and Sakthisekaran D: Protective role of Apigenin on the status of lipid peroxidation and antioxidant defense against hepatocarcinogenesis in Wistar albino rats. Phytomedicine 11: 309-314, 2004.

7. Romanová D, Vachálková A, Cipák L, Ovesná Z and Rauko P: Study of antioxidant effect of apigenin, luteolin and quercetin by DNA protective method. Neoplasma 48: 104-107, 2001.

8. Way TD, Kao MC and Lin JK: Apigenin induces apoptosis through proteasomal degradation of HER2/neu in HER2/neuoverexpressing breast cancer cells via the phosphatidylinositol 3-kinase/Akt-dependent pathway. J Biol Chem 279: 4479-4489, 2004.

9. Lindenmeyer F, Li H, Menashi S, Soria C and Lu H: Apigenin acts on the tumor cell invasion process and regulates protease production. Nutr Cancer 39: 139-147, 2001

10. Gupta S, Afag F and Mukhtar H: Selective growth-inhibitory, cell-cycle deregulatory and apoptotic response of apigenin in normal versus human prostate carcinoma cells. Biochem Biophys Res Commun 287: 914-920, 2001.
11. Chiang LC, Ng LT, Lin IC, Kuo PL and Lin CC: Antiproliferative effect of apigenin and its apoptotic induction in human Hep G2 cells. Cancer Lett 237: 207-214, 2006.

12. Czeczot H, Tudek B, Kusztelak J, Szymczyk T, Dobrowolska B, Glinkowska G, Malinowski J and Strzelecka H: Isolation and studies of the mutagenic activity in the Ames test of flavonoids naturally occurring in medical herbs. Mutat Res 240: 209-216, 1990.

13. Yin F, Giuliano AE, Law RE and van Herle AJ: Apigenin inhibits growth and induces G2/M arrest by modulating cyclinCDK regulators and ERK MAP kinase activation in breast carcinoma cells. Anticancer Res 21: 413-420, 2001.

14. Choi EJ and Kim GH: Apigenin causes G(2)/M arrest associated with the modulation of $\mathrm{p} 21$ (Cip1) and $\mathrm{Cdc} 2$ and activates p53dependent apoptosis pathway in human breast cancer SK-BR-3 cells. J Nutr Biochem 20: 693-690, 2008.

15. Chen X, Yeung TK and Wang Z: Enhanced drug resistance in cells coexpressing ErbB2 with EGF receptor or ErbB3. Biochem Biophys Res Commun 277: 757-763, 2000.

16. Tan M, Yao J and Yu D: Overexpression of the c-erbB-2 gene enhanced intrinsic metastasis potential in human breast cancer cells without increasing their transformation abilities. Cancer Res 57: 1199-1205, 1997.

17. Slamon DJ, Clark GM, Wong SG, Levin WJ, Ullrich A and McGuire WL: Human breast cancer: correlation of relapse and survival with amplification of the HER-2/neu oncogene. Science 235: 177-182, 1987.

18. Slamon DJ, Godolphin W, Jones LA, Holt JA, Wong SG, Keith DE, Levin WJ, Stuart SG, Udove J and Ullrich A: Studies of the HER-2/neu proto-oncogene in human breast and ovarian cancer. Science 244: 707-712, 1989.

19. Patel D, Shukla S and Gupta S: Apigenin and cancer chemoprevention: progress, potential and promise (Review). Int J Oncol 30: 233-245, 2007.

20. Lin JK, Chen YC, Huang YT and Lin-Shiau SY: Suppression of protein kinase $\mathrm{C}$ and nuclear oncogene expression as possible molecular mechanisms of cancer chemoprevention by apigenin and curcumin. J Cell Biochem (Suppl) 28-29: 39-48, 1997.

21. Way TD, Kao MC and Lin JK: Degradation of HER2/neu by apigenin induces apoptosis through cytochrome c release and caspase-3 activation in HER2/neu-overexpressing breast cancer cells. FEBS Lett 579: 145-152, 2005

22. Kanathur N, Shantaveerapa HN, Byrd RP Jr, Mehta JB and Roy TM: Non-tubercular mycobacterial pulmonary infection in immunocompetent men. South Med J 94: 719-723, 2001.

23. West KA, Castillo SS and Dennis PA: Activation of the PI3K/ Akt pathway and chemotherapeutic resistance. Drug Resist Updat 5: 234-248, 2002.

24. Carnero A, Blanco-Aparicio C, Renner O, Link W and Leal JF: The PTEN/PI3K/AKT signalling pathway in cancer, therapeutic implications. Curr Cancer Drug Targets 8: 187-198, 2008.

25. Ruiz PA and Haller D: Functional diversity of flavonoids in the inhibition of the proinflammatory NF-kappaB, IRF, and Akt signaling pathways in murine intestinal epithelial cells. J Nutr 136: 664-671, 2006.

26. Kim WK, Bang MH, Kim ES, Kang NE, Jung KC, Cho HJ and Park JH: Quercetin decreases the expression of ErbB2 and ErbB3 proteins in HT-29 human colon cancer cells. J Nutr Biochem 16: $155-162,2005$.

27. Lee WJ, Chen WK, Wang CJ, Lin WL and Tseng TH: Apigenin inhibits HGF-promoted invasive growth and metastasis involving blocking $\mathrm{PI} 3 \mathrm{~K} / \mathrm{Akt}$ pathway and beta 4 integrin function in MDA-MB-231 breast cancer cells. Toxicol Appl Pharmacol 226: 178-191, 2008.

28. Long X, Fan M and Bigsby RM: Apigenin inhibits antiestrogenresistant breast cancer cell growth through estrogen receptoralpha-dependent and estrogen receptor-alpha-independent mechanisms. Mol Cancer Ther 7: 2096-2108, 2008. 